\title{
frontiers
}

FOR YOUNG MINDS

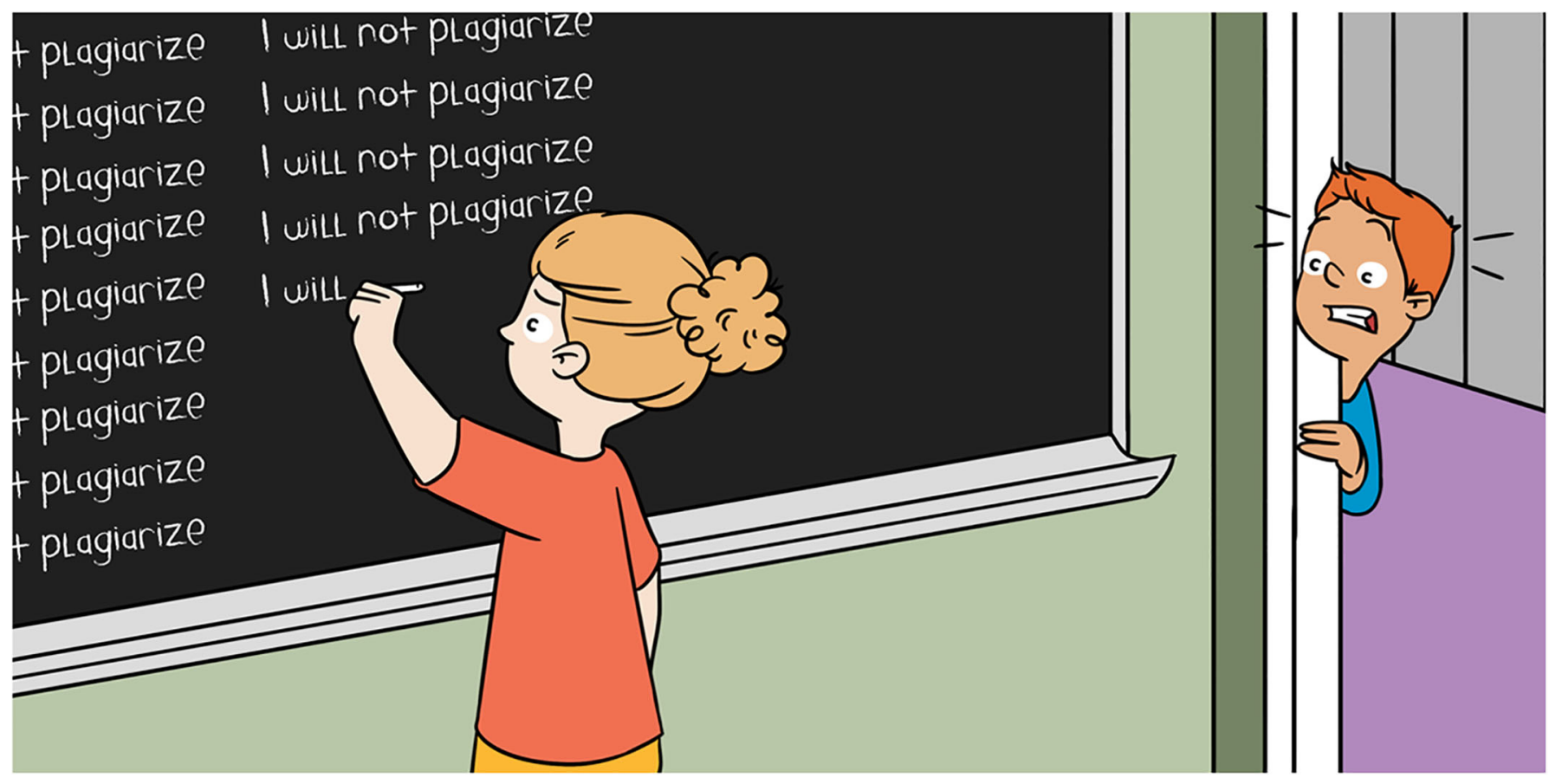

\section{SOCIAL LEARNING AND THE BRAIN: HOW DO WE LEARN FROM AND ABOUT OTHER PEOPLE?}

\section{Bianca Westhoff ${ }^{1,2^{*}}$, Iris J. Koele ${ }^{1,2}$ and Ilse H. van de Groep ${ }^{2,3,4}$}

${ }^{1}$ Department of Developmental Psychology, Institute of Psychology, Leiden University, Leiden, Netherlands

${ }^{2}$ Leiden Institute for Brain and Cognition, Leiden, Netherlands

${ }^{3}$ Department of Child and Adolescent Psychiatry, Amsterdam University Medical Center, Amsterdam, Netherlands

${ }^{4}$ Erasmus School of Social and Behavioural Sciences, Erasmus University Rotterdam, Rotterdam, Netherlands

YOUNG REVIEWERS:

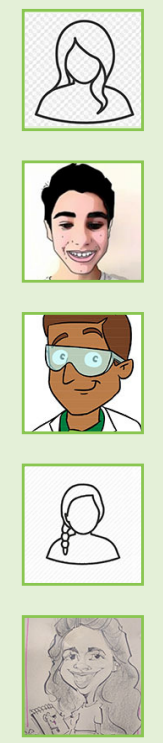

ANISHA

AGE: 13

ELI

AGE: 13

HENRI

AGE: 13

SARAH

AGE: 14

SPANDANA

AGE: 12
When you think about learning, you probably think about things you are taught at school. But have you ever realized you use a different type of learning as well, on a daily basis? This type of learning is called social learning, and it has to do with the people around you. That is, you learn from and about others by watching and interacting with them. For example, seeing someone else's mistakes may teach you to avoid falling into the same trap. Although social learning happens very often, you may not yet know much about it. However, social learning is very important because it helps us to learn more efficiently and to determine how best to behave around others. In this article, we introduce two different types of social learning, and explain how your brain plays an important role. 
SOCIAL LEARNING

Learning new information in a social context, with other people being the source of this information. Examples are learning from or about other people.

\section{WHAT IS SOCIAL LEARNING AND WHY IS IT IMPORTANT?}

When you think about the most recent thing you learned, the first thing that comes to mind is probably something you learned at school. For example, the French vocabulary you need to know for your upcoming test. Learning such things may be useful in the future: if you ever go to France on holidays, you will be able to ask for directions, for instance.

Clearly, learning knowledge (such as the French vocabulary) can be quite important. However, in addition to learning from books, you can also learn from and about the people around you. This is called social learning because, for this type of learning, people are the source. Most of the time, you are surrounded by other people, including your family, teachers, and school friends. Therefore, you probably learn from and about others every day, perhaps without even realizing it!

Because humans are such social beings, social learning is an important skill. Social learning is a very efficient way to learn things. For example, you do not have to figure everything out on your own, because you learn from other people's mistakes and successes. Also, social learning can enable you to get to know others better, and therefore to better understand how to behave around them. Such social learning skills help you to have good relationships with others, which is good for your well-being.

In this article, we explain two types of social learning: learning from other people and learning about other people. To show that you already use these types of social learning frequently, we will provide examples that you may encounter in school. Finally, because your brain plays a critical role in learning, we will explain how social learning works in the brain.

\section{HOW DO WE LEARN FROM OTHER PEOPLE?}

One important type of social learning is learning from someone else, by watching what they do. The idea is that other people's mistakes and successes can teach you whether you should behave the same way, or differently [1].

For example, imagine you are taking a test in school, but you just do not know enough of the answers to get a good grade. Your friend is sitting next to you, and you see she has already written down her answers. You may be tempted to take a quick look ... but then, suddenly, one of your classmates gets caught cheating and is punished. Now you will probably think more negatively about cheating, because you have seen that it may result in punishment! In 
other words, you have learned from someone else's mistake that it is better not to cheat during a test.

When you learn from watching other people, you are learning about the choices they make (such as cheating), and the results of those choices (such as punishment). If the results are positive, you are more likely to make the same choice. However, if the results are negative, you will probably make a different choice.

Scientists have discovered that people are good at learning about the best choices to make. However, we learn even better if we can also watch other people learning the same thing [1]. When we watch others' choices, whether the results are good or bad, we have extra information on what the best choice may be. We use that extra information to improve our own choices. So, we benefit from learning from others, as it helps us to make better choices ourselves. This makes learning from other people's mistakes and successes more efficient than figuring things out on our own.

\section{HOW DO WE LEARN ABOUT OTHER PEOPLE?}

We have just explained that people learn efficiently from other people, by watching them. Another common type of social learning is learning about other people, by interacting with them. When you learn about other people, you learn what they are like and how they behave. For this type of learning, you need to pay attention to other people's behavior so you can use this information in future decisions.

For example, imagine you tell one of your classmates that you like the boy sitting two tables away. However, it turns out your classmate is actually untrustworthy: your secret ends up being passed on to the entire class and you are very upset! In this case, you may have learned that it is better not to tell her your secrets again.

Although there are a lot of things you can learn about other people, many scientists study how we learn about other people's trustworthiness. Learning who you can trust is very important, because it helps you to decide whether you can believe the things a person says.

Scientists have discovered that, during the teenage years, we become better and faster at learning who we can trust and who does not deserve our trust [2]. So, during development, we become better at learning about others. This type of social learning therefore helps us to decide how to behave around others, which is necessary to build good relationships. 
Figure 1

Prediction errors result in learning. If there is a difference between what you expect to happen (expected result), and what actually happens (actual result), there is a prediction error. This prediction error is then used to update your knowledge: you have learned something new.

\section{PREDICTION ERROR}

The "surprise" when there is a difference between what you expect to happen, and what actually happens.

1 Want to know more about the calculations your brain does when you are learning something? Why not read [3]?

\section{VENTRAL STRIATUM}

Brain area that is, among others, involved in (social) learning because it calculates prediction errors.

MEDIAL

PREFRONTAL CORTEX (MPFC)

Brain area involved in, among others, social learning because when there is a prediction error, the MPFC updates your incorrect expectations in the brain with the new information you learned.

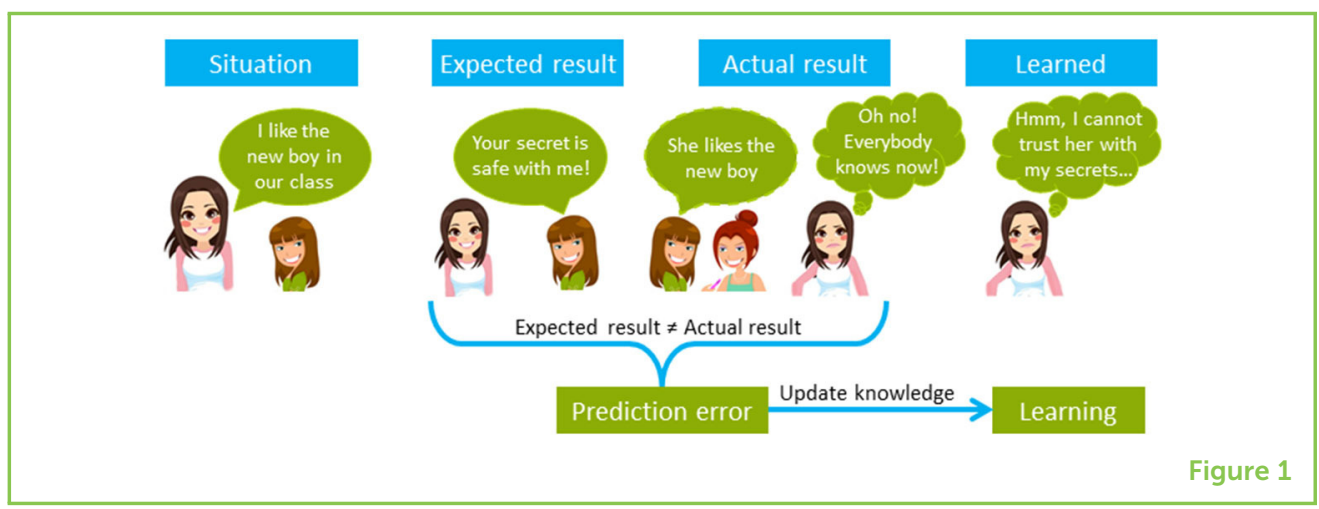

\section{HOW DOES SOCIAL LEARNING WORK?}

Now that we have introduced these two types of social learning, we will explain how social learning works. When you learn something, you are updating the things you know with the new information. Your brain is involved in this updating: it works like a calculator. That is, your brain is constantly calculating the difference between what you expect to happen, and what actually happens. If something unexpected happens, this may surprise you. The surprise is called a prediction error-you made a mistake (error) in what you predicted would happen. Your brain notes this prediction error and makes sure you learn from it, updating what you already know with the new information.

In the case of social learning, consider the example we discussed earlier, when you told your classmate about your secret crush (Figure 1). You expected her to keep quiet, but she did not. So, what happened was quite surprising because it was different from your expectation. Your brain notes the prediction error and uses this new information to update what you know about your classmate. That is, you have learned about your classmate, and you will not easily trust her with your secrets again ${ }^{1}$.

\section{WHICH PARTS OF THE BRAIN ARE INVOLVED?}

To make all the calculations necessary for social learning, several areas of your brain are used [4]. Scientists have discovered at least two brain areas that are important for social learning, called the ventral striatum and the medial prefrontal cortex (mPFC) (Figure 2). They made these discoveries by using an MRI scanner to scan people's brains. In Box 1, you can read more about how an MRI scanner works.

The ventral striatum is an area in the middle of the brain that you use when you make decisions, when you enjoy something, and when something is rewarding. Also, the ventral striatum is important for calculating prediction errors [4]. It is therefore an important brain area for regular learning and social learning. 
Figure 2

Brain areas involved in social learning. The ventral striatum (in the middle of the brain) calculates prediction errors, and these newly learned expectations are updated in the medial prefrontal cortex (mPFC, in the front of the brain). These two brain areas are therefore important in social learning.

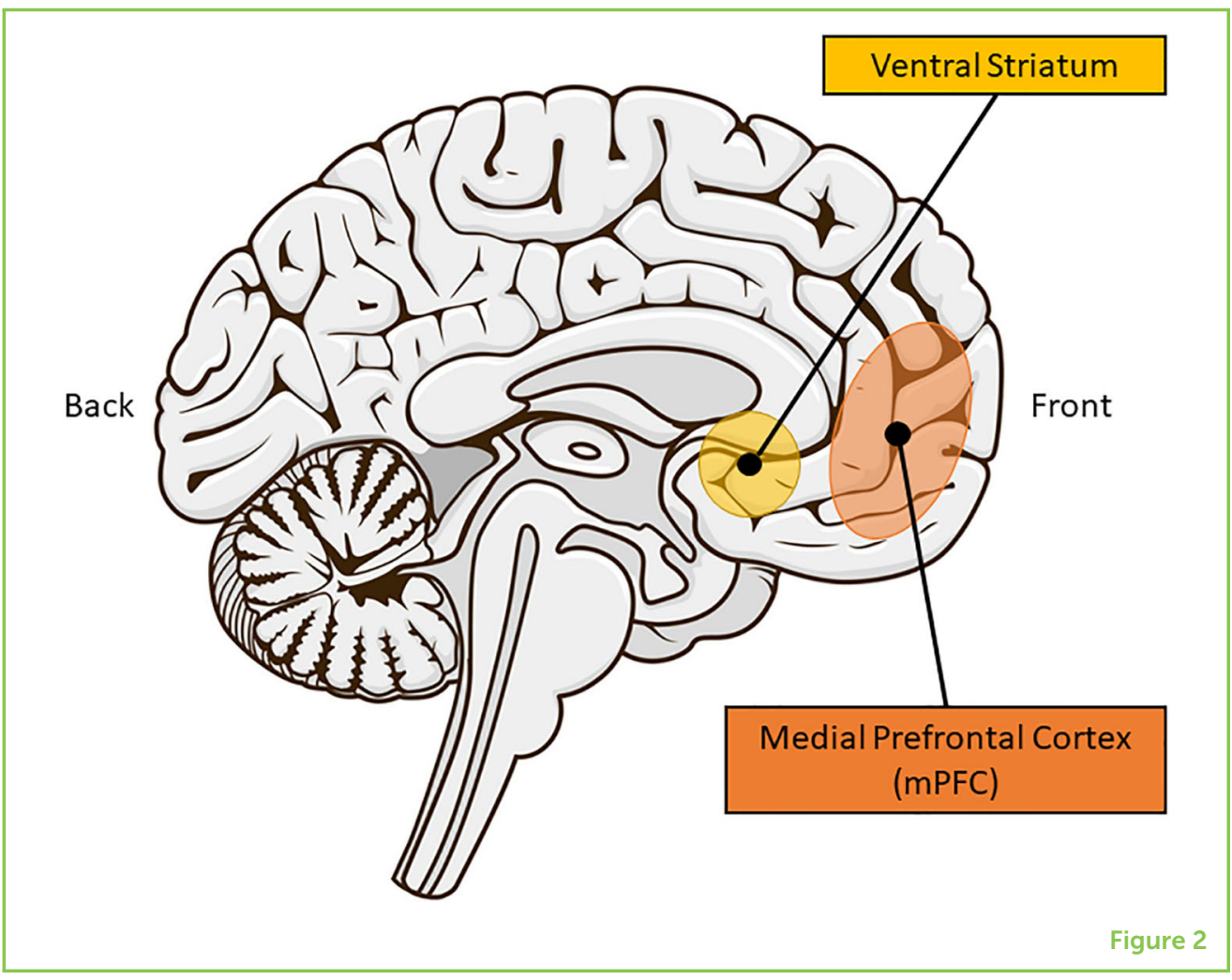

The MPFC is an area in the front of the brain (behind your forehead), that seems particularly important for thinking about what others are thinking, and for making decisions that involve other people. Also, the $\mathrm{mPFC}$ is involved in learning: After prediction errors are calculated by the ventral striatum, your MPFC updates the expectations you had with the new information [4]. The MPFC is, therefore, another important brain area for social learning.

So, the ventral striatum and the MPFC both play roles in social learning. However, it is important to realize that these brain areas are involved in other behaviors, in addition to social learning. Also, the ventral striatum and the mPFC are not the only parts of the brain used during social learning-many brain areas are involved. All these brain areas work together and communicate with each other while you are learning in complex social situations.

\section{RECAP: WHAT YOU HAVE LEARNED ABOUT SOCIAL LEARNING}

In this article, we have explained the two types of social learning and why social learning is an important skill. First, learning from other people's behavior and their resulting mistakes and successes is more efficient than figuring things out on your own. Second, learning about other people by interacting with them can help you to learn who you can trust and help you to build good relationships. When what 


\section{Figure 3}

Researchers use MRI scanners to study people's brains. A research setting in which one researcher positions a participant on a bed that will slide into the MRI scanner. Two other researchers are behind a computer screen, where they will see images of the participant's brain after they start the MRI scanner.
Box 1 | Studying the brain: how do we know what is going on there?

To understand how social learning works, many scientists study the brain using a magnetic resonance imaging (MRI) scanner (Figure 3). This scanner is a huge magnet that can take pictures of the brain through the skull. Scientists may use MRI to take pictures of someone's brain while that person is playing a computer game involving learning from or about others. In this way, scientists can find out which parts of the brain are involved during social learning. To find out more about how MRI scanners work and how they are used to study the brain, see [5].

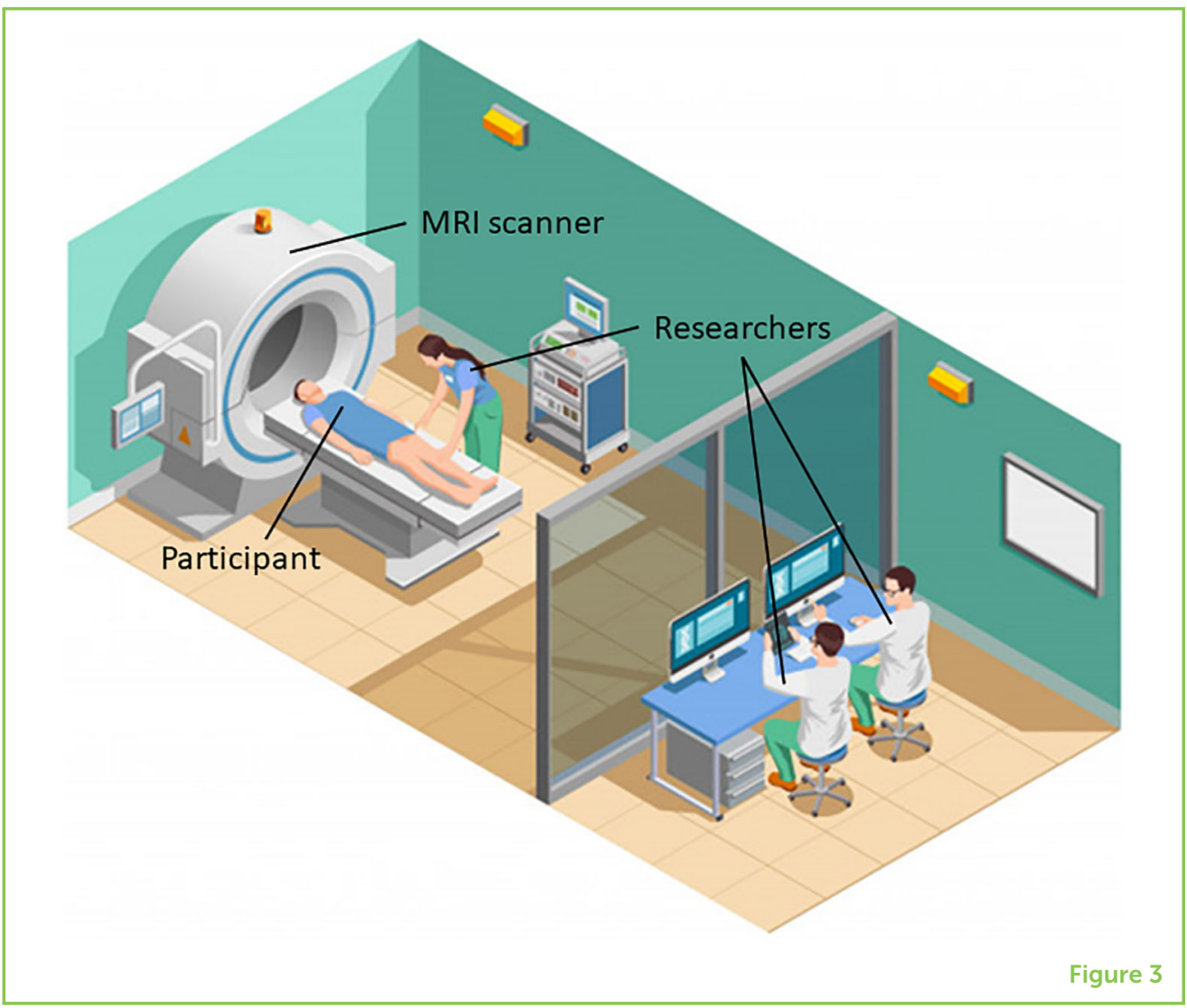

actually happens does not match what you predicted would happen, prediction errors are calculated in the brain, and these prediction errors result in learning. Prediction errors are calculated in the ventral striatum, which the MPFC uses to update the information already stored in the brain.

Now that you know more about social learning, perhaps you can think of your own examples of when you learned from or about others. Maybe you can think of ways social learning helped you to learn more efficiently, or to decide the best way to behave around others. The next time you watch or meet other people, think about the amazing calculations that are going on in your brain!

\section{ACKNOWLEDGMENTS}

We would like to thank those who assisted in the translation of the articles in this Collection to make them more accessible to kids 
outside English-speaking countries, and for the Jacobs Foundation for providing the funds necessary to translate the articles. For this article, the authors themselves translated it into Dutch as well. We would also like to thank Anna van Duijvenvoorde and Marieke Bos for comments on an earlier version of this article. BW was supported by an Open Research Area (ORA) grant (464-15-176) financed by the Netherlands Organization for Scientific Research (NWO), awarded to Dr. Anna C. K. van Duijvenvoorde. IK was supported by the NWO Westerdijk Grant (014.041.030), awarded to Prof. Berna Güroğlu. IG was supported by the Ammodo Science Award 2017 for Social Sciences, awarded to Prof. Eveline Crone.

\section{REFERENCES}

1. Bandura, A. 1977. Social Learning Theory. New York, NY: General Learning Press.

2. Van den Bos, W., van Dijk, E., and Crone, E. A. 2012. Learning whom to trust in repeated social interactions: a developmental perspective. Group Process. Intergroup Relat. 15:243-56. doi: 10.1177/1368430211418698

3. Nussenbaum, K., and Cohen, A. 2018. Equation invasion! How math can explain how the brain learns. Front. Young Minds 6:65. doi: 10.3389/frym.2018.00065

4. Joiner, J., Piva, M., Turrin, C., and Chang, S. W. 2017. Social learning through prediction error in the brain. NPJ Sci. Learn. 2:8. doi: 10.1038/s41539-017-0 009-2

5. Hoyos, P. M., Kim, N. Y., and Kastner, S. 2019. How is magnetic resonance imaging used to learn about the brain? Front. Young Minds 7:86.

doi: 10.3389/frym.2019.00086

SUBMITTED: 30 October 2019; ACCEPTED: 19 June 2020;

PUBLISHED ONLINE: 05 August 2020.

EDITED BY: Jessica Massonnie, University College London, United Kingdom

CITATION: Westhoff B, Koele IJ and van de Groep IH (2020) Social Learning and the Brain: How Do We Learn From and About Other People? Front. Young Minds 8:95. doi: 10.3389/frym.2020.00095

CONFLICT OF INTEREST: The authors declare that the research was conducted in the absence of any commercial or financial relationships that could be construed as a potential conflict of interest.

COPYRIGHT @ 2020 Westhoff, Koele and van de Groep. This is an open-access article distributed under the terms of the Creative Commons Attribution License (CC BY). The use, distribution or reproduction in other forums is permitted, provided the original author(s) and the copyright owner(s) are credited and that the original publication in this journal is cited, in accordance with accepted academic practice. No use, distribution or reproduction is permitted which does not comply with these terms. 

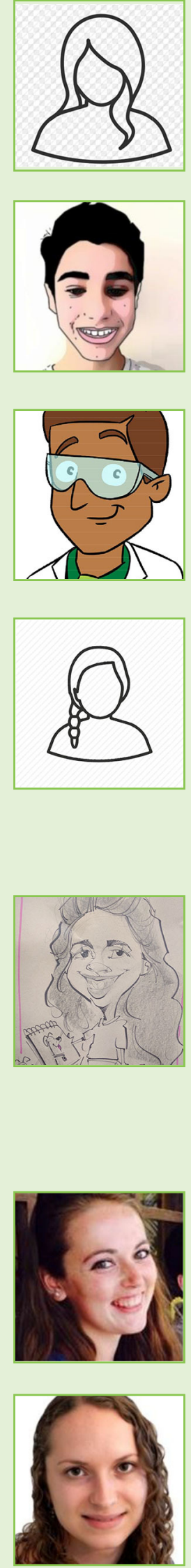

\section{YOUNG REVIEWERS}

\section{ANISHA, AGE: 13}

I am a seventh grader at Synapse School. I am passionate about neuroscience, quantum physics, mathematics, and singing!

\section{ELI, AGE: 13}

I am a seventh grader at Synapse School. I enjoy cooking, baking, and reading.

\section{HENRI, AGE: 13}

I am an eighth grader at Synapse school. I enjoy reading Frontiers articles.

\section{SARAH, AGE: 14}

I am an eighth grader at Synapse School who loves anything related to math, science, or the outdoors, from testing chemical reactions in the kitchen to finding the distance I covered and my average speed while skiing down a mountain. Though I love running around and exploring new things, I also enjoy simpler parts of my day where I can sit with my cat and read. Balancing these activities keeps me engaged with life but also calm.

\section{SPANDANA, AGE: 12}

My name is Spandana. My favorite subject in school is science. My best friend is imagination and I love to write stories. Some of my hobbies are talking, watching TV, playing volleyball, and drawing. I love animals and dogs are my favorite. I like to ask questions. My favorite colors are teal and purple.

\section{AUTHORS}

\section{BIANCA WESTHOFF}

I am a researcher at Leiden University in the Netherlands. I am interested in how we learn about the people around us. Also, I study the brain and how it develops during the teenage years. I am especially interested in how this brain development affects the ways we behave and learn about others. *b.westhoff@fsw.leidenuniv.nl

\section{IRIS J. KOELE}

I am a researcher at Leiden University in the Netherlands. I am particularly fascinated by the way teenagers learn from their friends and other classmates, how these social relationships change over time, and what happens in the brain during this sort of learning. Furthermore, I am interested in what happens in the brain when young people with an attention deficit and hyperactivity disorder win rewards for themselves and for their friends. 


\section{ILSE H. VAN DE GROEP}

I am a researcher at Erasmus University Rotterdam, and the Amsterdam UMC in Amsterdam, in the Netherlands. I am interested in understanding why some people show persistent antisocial behavior (such as aggression) throughout their lives, whereas others do not. To be able to understand these differences, I look at the brain and behavior of young adults who were arrested for a crime when they were children. Amongst other things, I am curious to find out whether social learning and decision-making works differently in these individuals. 